\title{
LA COMUNICACIÓN POPULAR COMO ESCENARIO DE PRAXIS PARA EL TRABAJO SOCIAL COMUNITARIO*
}

\author{
POPULAR COMMUNICATION AS A PRAXIS SCENARIO FOR \\ COMMUNITY SOCIAL WORK
}

\section{Carlos Lasso-Urbano**}

\section{Resumen}

Objetivo. El presente artículo expone la importancia de la comunicación popular como estrategia ético-política e innovadora en el ejercicio profesional del trabajo social comunitario. Metodología. Su exposición se realiza desde dos momentos: primero, desde el abordaje conceptual e histórico de la misma, integrando categorías como trabajo, comunicación, alienación, identidad, conciencia y lo urbano-popular; segundo, se examina la relación de la comunicación popular con el trabajo comunitario, para lo cual se describen sus características, aportes, particularidades, formas de manifestación social, evidenciándose la necesidad que existe de integrar sus componentes teóricometodológicos a los planes de estudio de formación profesional. Resultados. Se presenta la manera en que puede utilizarse en el marco de las luchas sociales y en la ofensiva contrahegemónica que deviene de los sectores urbano-populares. Conclusión. Los dos momentos se constituyen en aspectos esenciales para comprender la comunicación popular como escenario de praxis del trabajo social comunitario.

Palabras clave: comunicación popular, trabajo social comunitario, praxis, formación profesional.

\begin{abstract}
Objective. This article intends to show the importance of popular communication as an ethicalpolitical and innovative strategy in the professional practice of community social work. Methodology. The presentation was carried out in two stages: the first stage is considered from its conceptual and historical approach integrating categories such as work, communication, identity, alienation, awareness, and the urban popular. The second stage examines the relationship of popular communication with community work, for which the characteristics, contribution, particularities, and ways of social manifestation are described, evidencing the need that exists to integrate its theoretical-methodological components into the plans of study of professional training. Results. The way in which it can be used in the context of social struggles and in the counter-hegemonic offensive coming from urban popular areas is presented. Conclusion. Those two stages constitute essential aspects to understand popular communication as a scenario for the praxis of community social work.
\end{abstract}

Key words: popular communication, community social work, praxis, vocational training.

\footnotetext{
* El presente artículo hace parte de los estudios realizados en la maestría en Ciencias Sociales de la Universidad de Caldas, al igual que de la reflexión desarrollada del trabajo organizativo y comunitario adelantado como profesional durante varios años con comunidades y organizaciones sociales desde la comunicación popular.

*** Universidad Simón Bolívar. Cúcuta, Colombia. E-mail: lbca12123@hotmail.com.

(D) orcid.org/0000-0001-5407-1953. Google Scholar
}

rev. eleuthera. 21, julio-diciembre 2019, 152-167

Recibido: 25 de octubre de 2018. Aprobado: 10 de mayo de 2019.

ISSN: 2011-4532 (Impreso) ISSN: 2463-1469 (En línea) DOI: 10.17151/eleu.2019.21.9. 


\title{
Introducción
}

Las contradicciones que caracterizan a la sociedad contemporánea han conllevado a que las manifestaciones de la "cuestión social” se tornen cada vez más profundas, a que surjan otras nuevas y que el capitalismo se vuelva cada vez más devastador, siendo los sectores populares los más afectados, pues la mercantilización de los derechos sociales, la precarización y explotación laboral, la apropiación de los recursos naturales que terminan siendo convertidos por parte de las multinacionales con el apoyo de los gobernantes locales, regionales y nacional en simples mercancías de producción y explotación como estrategia para subsanar la crisis que vive el capitalismo, están conllevando al deterioro de la vida misma.

Ante el panorama general descrito, las comunidades han tenido que integrar la resistencia social como aspecto insoslayable de sus vidas cotidianas, con el fin de defender el derecho a permanecer en sus territorios, resistiendo a la ofensiva del capital para exigirle al Estado colombiano respuestas certeras ante el abandono de este, que ha conllevado a la profundización de los problemas sociales y a la reproducción de las relaciones imperantes. Este es el escenario en que nos encontramos también inmersos los trabajadores sociales y, en especial, aquellos que adelantamos procesos con comunidades y organizaciones sociales. Por lo tanto, el compromiso con las poblaciones con quienes desarrollamos nuestro quehacer profesional debe ser del tamaño del sol, como diría Roque Dalton y como señala Iamamoto (2003):

\begin{abstract}
Uno de los mayores desafíos que vive el Asistente Social en el presente es desarrollar su capacidad de descifrar la realidad y construir propuestas de trabajo creativas y capaces de preservar y tornar efectivos los derechos, a partir de las demandas emergentes en el cotidiano. En fin, ser un profesional propositivo y no sólo ejecutor. (p. 33)
\end{abstract}

El ser un profesional propositivo implica ir más allá de las rutinas institucionales y de las acciones meramente laborales; significa intentar aprehender el movimiento de la realidad concreta, identificando oportunidades reales presentes en esta que pueden llegar a ser impulsadas por el trabajador social. De acuerdo con lo anterior, la comunicación popular aparece como estrategia orientada a visibilizar la vida de las comunidades desde los sujetos mismos que la hacen posible y, adicional a ello, para contribuir a la formación, organización y movilización de los sectores urbano-populares, por lo que se constituye en mecanismo para hacer visibles los problemas que enfrentan los individuos y las capacidades con las que cuentan que por lo general son invisibilizadas. En sintonía con lo anterior, es importante reconocer las formas de comunicación de las comunidades y organizaciones sociales, integrando aspectos como participación social, intervención social, lo colectivo, lo popular, investigación-acción, y lo político-pedagógico;

\footnotetext{
${ }^{1}$ Para José Paulo Netto, la "cuestión social” es expresada por las contradicciones del desarrollo del capitalismo monopolista. Ver más en "Cinco notas a propósito de la 'cuestión social”" (2003).
} 
La comunicación popular como escenario de praxis para el trabajo social comunitario

igualmente, le corresponde al profesional apropiarse teórica y metodológicamente de la misma, en aras de contribuir al desarrollo de propuestas comunicacionales surgidas desde el interior de la comunidad.

\section{Discusión}

\section{Abordaje histórico de la comunicación}

Para abordar la comunicación históricamente, es necesario hablar de las acciones y condiciones materiales de vida de los hombres, puesto que estos son tal y como manifiestan su vida en los diferentes estadios de la naturaleza y no una concepción idealista que actúa con hombres irreales, aislados del proceso histórico, los cuales "descienden del cielo sobre la tierra, arrancándoles de su proceso de vida sus condiciones reales" (Marx y Engels, 1976, p. 8) y, de ese modo, sus vidas reales son remplazadas por la abstracción y la especulación, lo que lleva a que la conciencia sea vista como elemento que tiene vida, como si fuese un individuo, lo que provoca la separación de la historia real de la vida humana.

Hay que partir de premisas reales, teniendo claridad de cómo actúan, producen materialmente y desarrollan sus actividades los individuos, ya que lo que son, depende totalmente de las condiciones materiales de producción; a medida que comienzan a producir sus medios de vida, se diferencian de los animales, pues transforman su realidad, su pensamiento y los productos concretos del mismo y empiezan a desarrollar la comunicación.

No obstante, para abordar la esencia de la comunicación en el ser social, se deben resaltar las condiciones de existencia de los individuos, manifestándose en sus acciones por medio del trabajo, este entendido como la condición básica y fundamental de toda la vida humana, pues permite que los hombres se desarrollen, y es, además, el elemento encargado de crear históricamente al propio hombre. La comunicación no puede ser abordada aislada del trabajo, debido a que esta es una cualidad, una manifestación permanente del mismo.

\section{El papel del trabajo en el desarrollo de las fuerzas productivas y en la construcción del ser humano}

La realidad concreta se encuentra supeditada a un conjunto de determinaciones que dirigen las relaciones de los sujetos con la naturaleza; la historia construida por el individuo se expone como elemento esencial de su desarrollo, en medio de virajes que posicionan la narrativa económica, social, política, cultural y ambiental, como mediaciones importantes para el "reconocimiento universal" de los momentos que atestiguan los vastos cambios de la sociedad. Reconocer el trabajo como categoría central, permite vislumbrar la dialéctica de las relaciones sociales; reconocer el trabajo como proceso entre la naturaleza y el hombre contribuye a 
entender cómo este actúa en la naturaleza y cómo se transforma y transforma esta misma, mediante un determinado modo de producción de su vida material (manifestado en herramientas, mercancías, entre otros), que además le permite producir sus representaciones, visiones e ideas. En síntesis, el comportamiento de la naturaleza aporta al surgimiento del trabajo concebido a partir de la producción de herramientas.

El trabajo creó al hombre, generó su actividad conjunta, permitió que los individuos tuviesen la necesidad de decirse algo, ante lo cual se desarrolla el lenguaje, que aparece como medio de comunicación y a la vez como forma de representar el mundo. El lenguaje contribuye en el desarrollo de la comunicación que el hombre construye a partir del trabajo, que permite la objetivación de la vida humana, lo que lleva a que el individuo logre concebirse como un ser entre otros seres, contribuyendo a la objetivación de capacidades, intelectuales y físicas, siendo el elemento generador de la liberación real de toda creatividad y el desarrollo concreto de su imaginación.

Así mismo, como alude Infranca (2006), el trabajo se constituye en fundamento de una comunidad humana, debido a que permite construir relaciones, aportando a "describir la esencia necesaria del ser humano, su capacidad de vivir en comunidad" (p. 2). El trabajo es la mediación existente entre el hombre y la naturaleza, entre el hombre y la sociedad; es el medio a través del cual se da el mejoramiento del conocimiento humano, contribuyendo en el desarrollo de la esencia genérica necesaria del individuo.

Pero el capitalismo se ha encargado de crear y reproducir una concepción distinta del trabajo, desconociendo su carácter ontológico (es decir no reconociéndolo como fundamento del ser social, que conduce a los hombres a desarrollar su capacidad de trabajar, adquiriéndose a través de un proceso histórico de forma colectiva) y convertido en una simple herramienta para el enriquecimiento de las élites; para ello, se ha recurrido a la división del mismo, lo que ha originado una separación entre el trabajo material y el trabajo intelectual, dándose así la separación entre el interés particular y el común, lo que produce que cada quién realice un tipo específico de actividades que le vienen impuestas y originándose la apropiación privada de la ganancia entre unos pocos (la plusvalía).

El trabajo condicionado por las relaciones sociales burguesas es concebido simplemente como la fuente de toda riqueza, lo que lleva al individuo a no reconocerse en lo que produce, concibiéndolo como un objeto ajeno a él, por lo que el extrañamiento se ve representado no sólo en el resultado, sino también en el acto de la producción, es decir, dentro de la actividad productiva. El capitalismo ha desarrollado una división del trabajo mental y manual que produce la división de la humanidad en clases sociales, contribuyendo a la alienación y exclusión de la mayoría. 
En la actualidad, el trabajo solo significa para el individuo explotación, castigo y muerte, siendo inútil realmente para quién trabaja y cada vez más individualizado para el trabajador; este actualmente es un trabajo alienado, pues el trabajador no se encuentra liberado de las exigencias que emite la actividad continua de reproducción, estando exento de las cosas que le permitan reflexionar sobre la naturaleza del ambiente, de su propio dominio.

El trabajo alienado es entendido como la no apropiación de la riqueza material y espiritual por parte del individuo, esto provoca la negación absoluta de sí mismo y de su entorno, convirtiéndose en algo que no es voluntario sino forzado. En consecuencia, esto lleva al trabajador a realizar una actividad que no es suya, sino que pertenece a otro, conduciéndolo así a la pérdida de sí mismo. Este tipo de trabajo le arranca al hombre el objeto de su producción además de su vida genérica ${ }^{2}$; lo que se sintetiza en el extrañamiento del producto de su trabajo y de sí mismos, en otros términos, lo que hace la clase dominada es producir y reproducir socialmente su miseria a partir de la objetivación de la materia prima que es transformada en mercancía, aquella acción le provoca una fuerza extraña al sentirse ajeno de lo que él produce.

El fenómeno de la alineación es un hecho reiterativo en el capitalismo, principalmente en la "clase que vive del trabajo", pues el trabajo alienado, no contribuye al movimiento ascendente de la conciencia, no le permite al individuo tomar posición de sí mismo y de la naturaleza que lo rodea, pues representa injusticia, desdicha, dominación, genera tristeza y contribuye a que el individuo no se reconozca como motor de la historia, conduciendo al trabajador a crear el mundo sin argumento y a la negación absoluta de sí mismo y de su entorno.

Cabe señalar que la lucha para combatir la concepción burguesa del trabajo y el capitalismo no debe entenderse como una lucha contra frases, puesto que entonces se estaría cayendo tal como aluden Marx y Engels (1976) en “oponer a las frases combatidas más que otras frases y al combatir solamente las frases de este mundo, no se combate en modo alguno el mundo real existente” (p. 14). No hay que perder de vista las condiciones reales de los hombres históricos, ni mucho menos su proceso de vida material, por lo que se debe partir de sus condiciones de vida actuales, aquellas que los mantienen inmersos en la dominación a través del trabajo, que cosifican sus acciones y su pensamiento.

La liberación del individuo solo se logra materializar en el mundo real y a través de medios reales, pues esta debe ser ante todo un acto histórico. Es por eso, que la liberación debe partir desde la acción práctica del individuo, de aquel que tiene su proceso histórico, desde su producción material y no desde lo que éste dice o piensa, debido a que "no es la conciencia la que determina la vida, sino la vida la que determina la conciencia” (Marx y Engels, 1976, p. 21),

\footnotetext{
${ }^{2}$ La vida genérica se entiende como la posibilidad de entender el mundo y crear una visión del mismo.

${ }^{3}$ Para profundizar más en este aspecto ver ¿Adiós al Trabajo? de Antunes (2001).
} 
y el trabajo no alienado aparece como la primera manifestación del movimiento ascendente de la conciencia.

\section{El desarrollo de la conciencia y la comunicación como herramienta para la superación de la alienación}

El desarrollo de la conciencia permite superar el estado de alienación, esta entendida como esa forma en que el sujeto toma posición de sí mismo y de la naturaleza que lo rodea, existiendo así una clara aprehensión del sujeto en su yo y la relación estrecha con las determinaciones que le permiten esa relación con el otro. La conciencia aparece en el trabajo, cuando el trabajador se reconoce y construye una idea propia del mundo objetivo, cuando se asume como trabajador y se reconoce como explotado, considerando que la función que desempeña no le satisface y toma posición frente a la misma.

La conciencia como estado en el que predomina la mediación del trabajador con la realidad, en cuanto estriba que su comportamiento obedece a una fuerza dependiente que le impide ejercer su libre albedrío de cara a la realidad que lo afecta.

La conciencia es, ante todo, naturalmente, conciencia del mundo
inmediato y sensible que nos rodea y conciencia de los nexos limitados con
otras personas y cosas, fuera del individuo consciente de sí mismo; y es, al
mismo tiempo conciencia de la naturaleza. (Marx y Engels, 1976, p. 22)

La conciencia es condición esencial para superar el estado de alineación y una de las formas para hacerlo es la búsqueda del ser genérico, que se define como la relación directa con el sí mismo, cuya característica es superar el extrañamiento para que el sujeto se sienta parte del mundo como ser universal y libre, desmitificando las contradicciones de la realidad que habita, constituyendo los argumentos necesarios para confrontar su mundo, reconociendo el conjunto de particularidades del medio donde comparte su existencia y, por ende, acercándose a la esencia y naturaleza de su realidad, lo que al mismo tiempo funciona para identificar el ser de la realidad concreta. El desarrollo de la conciencia permite objetivar la libertad, en la lucha constante por reconocerse y hacerse reconocer, logrando esa identidad de lo conocido que es su entorno y su autorreconocimiento.

Para poner en práctica el desarrollo de la conciencia, aparece la comunicación, siendo cualidad necesaria del trabajo y manifestación permanente del mismo; identificándose, además, como actividad real, productiva, objetiva, subjetiva y a su vez consciente. La comunicación, al igual que el trabajo, contribuye a transformar y humanizar la naturaleza y a crear relaciones sociales. Es elemento de intercambio que aporta a que los hombres se objetiven, por lo tanto, no se puede entender la comunicación separada del trabajo. Para Abad (2006), la comunicación: 


\begin{abstract}
Es un organismo viviente. Nos compete comprenderla, no sólo como producto de las relaciones humanas sino como manifestación permanente del trabajo en relación con la materia, las ideas y las emociones en una época y sociedad concretas con circunstancias específicas y siempre colectivas. (p. 116)
\end{abstract}

No debe pensarse como algo inmediato sino como un proceso histórico y un estado de construcción permanente. Para que en verdad se pueda hablar de comunicación, se requiere que los diálogos entre "emisor" y "receptor" se encuentren en intercambio indisoluble y donde ninguno de los dos sea el propietario exclusivo del proceso ni del producto que se desarrolla. La comunicación permite el reconocimiento, es necesidad constitutiva de las relaciones sociales, ya que aporta en la construcción de estas, además de ser elemento de la evolución humana y herramienta del trabajo. En conclusión, la comunicación en su expresión más amplia significa trabajo.

En el capitalismo, la comunicación se encuentra alienada, pues no existe igualdad alguna para discursos iguales y mucho menos se manifiesta como proceso entre iguales. Se encuentra representada a través de reducciones, puesto que como la manifiestan Marx y Engels (1976):

La clase que tiene a su disposición los medios para la producción material, dispone con ello, al mismo tiempo, de los medios para la producción espiritual, lo que hace que se le sometan, al propio tiempo, por término medio, las ideas de quienes carecen de los medios necesarios para producir espiritualmente. (p. 45)

Con lo cual las ideas de las clases dominantes son las únicas que aparecen de lo que se entiende como comunicación; aquí se utiliza, para abaratar la fuerza de trabajo y de ese modo hacerla manejable y se sienta agradecida. Se recurre a ella para vender bienes y servicios y reproducir valores morales burgueses. Es utilizada para el control del pensamiento y lenguaje de las masas, introducirlas en el consumismo más despiadado y como medio y fin para garantizar el dominio hegemónico del capitalismo en la vida cotidiana, envolviendo la realidad concreta en un velo ideológico, con lo que se reproduce una interpretación falsa de ésta, aprovechándose para desviar al individuo de lo real, prohibiendo su actividad mental, orgánica, participativa y creándole el significado acerca de su mundo. Al reemplazar lo real por lo irreal mediante el simulacro, quien seduce la cultura, reproduce la forma de pensamiento y enajena la conciencia.

Las clases dominantes han desarrollado su visión de la comunicación para consolidar su imagen, identidad y hegemonía, siendo atribuidas a toda la sociedad a nivel de los distintos ámbitos de la vida colectiva y particular. Es utilizada para el sometimiento ideológico masificado, como medio mercenario que se encarga de vender espacios y tiempos al espectador, orientada por los medios de comunicación dominantes, quienes se construyen sobre la base del capital, por 
lo cual, cumplen una función desorganizadora y desmovilizadora de la clase dominada, creando representaciones colectivas desde la dominación.

La comunicación en el capitalismo no implica libertad para todos, ya que la clase dominante al ser la dueña de esta también es dueña del lenguaje, entendido este como las distintas formas en que el individuo comunica: signos, símbolos, códigos, ideas, etc. No se puede ver por separado el lenguaje del trabajo, pues estos representan "el pasaje del ser natural al ser social. Pero el trabajo aparece como el momento dominante en tal pasaje”. (Lukács como se citó en Infranca, 2006, p. 84).

Las clases dominadas han vivido sometidas al despojo de la comunicación, siendo presentada y reducida simplemente a la publicidad y la publicidad no es comunicación. "Ha sido suplantada para que abandonemos toda noción y esperanza de igualdad y comunidad, ha sido degenerada por un plan modelador de conciencias, planeado con el rigor de las armas y para el control social" (Abad, 2006, p. 114), siendo asaltada y concibiéndose en su lugar como hecho inmediato. Sólo permite el intercambio de ideas, códigos, símbolos que el modelo ha creado para la dominación y para velar la lucha de clases, al no permitir la evaluación colectiva y permanente del mundo, potenciando la incapacidad de los individuos para comunicarse.

Se utiliza como herramienta para la reproducción del trabajo alienado, así como de las relaciones sociales burguesas. Lo que se concibe actualmente como comunicación, refleja constantemente la relación de dominación y subordinación que se da en todas las esferas de la vida social.

\section{Lo popular como construcción de la comunicación no alienada}

En la tarea de construir un tipo de comunicación no alienada, que aporte a generar reciprocidad, participación, diálogo, que parta de la cultura y de las necesidades de las comunidades y del propio individuo, transformando las características de la comunicación dominante, lo popular desempeña un papel fundamental. Visto como escenario reproductor de la cultura, allí se construyen los procesos sociales, se hace posible históricamente lograr abarcar y comprender el sentido que adquieren los proyectos de comunicación, ubicándola como mediación social y teórica de la comunicación popular.

Algunos estudiosos de lo popular como García Canclini construyen unos atisbos a partir de la situación de "subalternidad” y su ubicación en las relaciones sociales, es decir, el estudio de los de abajo, los marginados, los de la periferia en la que se suscita una relación estructural, política, económica, cultural... etc., de su devenir y no meramente se explaya el interés del folklore por despojar su capital simbólico y señalar en un sentido deductivo lo popular. En esta línea, lo popular no puede seguir entendiéndose como resultado de la tradición, debido 
La comunicación popular como escenario de praxis para el trabajo social comunitario

a que la industria cultural homogeniza rasgos que terminan por convertirse en instrumentos de poder para manipular la concepción real de lo popular. Desde los postulados inspirados en Gramsci, lo popular no se define como un repertorio de tradiciones sino como una posición de clase frente a lo hegemónico, este como una forma de resistencia caracterizada por los avatares inusitados por la dominación y hegemonía de canales de información que minan la realidad.

El valor de lo popular no reside en su autenticidad, sino en su representatividad sociocultural, es decir,

En su capacidad de materializar y de expresar el modo de vivir y pensar de las clases "subalternas", las maneras como sobreviven y las estratagemas a través de las cuales se filtran, reorganizan lo que viene de la cultura hegemónica, y lo integran y funden con lo que viene de su memoria histórica. (Barbero, 1983, p. 85)

Por tanto, lo popular es hoy un escenario fértil para transformar la estructura compleja de la cultura y para la construcción de una comunicación con carácter popular, esa que brinde espacios para la puesta en práctica de la participación real de los individuos, donde intervienen sobre todo aquellos que no tienen el derecho de expresarse ${ }^{4}$. De ese modo, hablar de comunicación popular es hablar de comunicación en dos sentidos:

De las clases populares entre sí (y cuando digo clases estoy entendiendo los grupos, las comunidades, incluso los individuos que viven una determinada situación de clase), pero estoy hablando también de la comunicación de las clases populares con la otra clase. Con aquella otra contra la cual se definen como subalternas, como dominadas. (Barbero, 1983, p. 5)

Si bien es necesario partir desde el debate de lo popular como categoría esencial de la comunicación popular, es menester entender desde una postura dialéctica que hoy en día no existe solamente un actor histórico (llámese clase social) que se encuentre aspirando a una hegemonía exclusiva. Se tienen una diversidad de actores al igual que una expresión de intereses de clase muy compleja, si bien se incluye a los trabajadores, se encuentran además sectores de la población constituida por el sector informal, pequeños comerciantes, campesinos, amas de casa, maestros, estudiantes, personas que cuentan con una vinculación laboral estable y las que no devengan un salario, entre otros.

\footnotetext{
${ }^{4}$ Sin voz se asocia a alienación, a imposibilidad de reconocer el extrañamiento que el sistema de explotación produce tanto respecto del fruto del trabajo apropiado como de los valores, ideas y tradiciones de los grupos excluidos del poder.
} 
Son sectores que pese a acceder a algunas ventajas de la ciudad o el campo, cuentan con limitaciones para participar de los valores y normas predominantes en este escenario que caracterizan a la cultura urbana-rural. Para Jaramillo (2012), aquellos sectores hacen parte de lo que va a denominar el campo urbano-popular, los cuales no son una clase social, sino que se ocupan de diversas posiciones en el ámbito económico, político, social y cultural. Así pues, las clases y sectores urbano-populares son:

\begin{abstract}
Un conjunto de agentes organizados en diversas formas, que establecen relaciones entre sus diversos miembros de competencia, negociación, coalición. En el campo urbano-popular entrena agentes adscriptos a determinadas posiciones sociales, quienes se caracterizan por poseer una posición estructuralmente subordinada. En la formación social nacional, en el conjunto de las especies de "capital” (económico, social, político, cultural), se hallan en un cuádruple proceso de exclusión, o en todo caso, de apropiación parcial. (Jaramillo, 2012, p. 15)
\end{abstract}

En el campo urbano-popular se expresan luchas en el ámbito individual y organizativo, debido a las contradicciones e intereses predominantes. Ahí se busca reproducir una normativa, unos valores, unos imaginarios, una visión de mundo desde lo político, económico, social y cultural, de acuerdo con una determinada forma de vida que va en contraposición del campo hegemónico.

Es en ese sentido, que las clases y sectores urbano-populares deben articularse al análisis de la comunicación popular, ya que esta se plantea como escenario de participación, educación, concientización, organización, movilización y construcción de realidad social, política, económica y cultural, que desde espacios locales permite la producción, distribución y acceso a los medios de comunicación, desde y para los sectores populares; en la medida que se construye a través de lenguajes que fortalecen la identidad y el reconocimiento de diversas expresiones culturales.

Aparece como necesidad colectiva de contar con herramientas de comunicación, participativas e incluyentes que hagan visibles las capacidades colectivas de los sectores urbanos populares, que liberen, expresen, posibiliten la palabra, los pensamientos y saberes, que de alguna manera no se encuentran reflejados en la comunicación masiva hegemónica. Esto busca contribuir a que los sujetos logren describir su identidad y el dominio simbólico, trascender lo inmediato y alcanzar la expansión de sus libertades comunicacionales, devenidas desde la misma comunidad organizada.

Se constituye en instrumento de resistencia ante las apariencias y abstracciones del mundo, como crítica verdadera e inalienable, ante la industria cultural que impera en la globalización, 
los medios masivos de comunicación y en toda la sociedad capitalista y que trae consigo la apariencia de la libertad, la cual se manifiesta como una ambigua apariencia de la cultura. La comunicación popular es el elemento que genera solidaridad, capacidad de decisión, defensa de los intereses de los sectores urbano-populares, contribuyendo al desarrollo de la conciencia del individuo, aportando además a cambiar la lógica del sistema capitalista, que es también la lógica de la comunicación hegemónica; se convierte en la herramienta para el fortalecimiento de las luchas populares. En síntesis, la comunicación popular es el elemento que aporta a la politización de las clases y sectores urbano-populares, conllevando a la organización social para de esa forma ir desarrollando el ser genérico e ir superando el estado de alienación a la que ha conducido al individuo la dominación impuesta desde el capitalismo.

\section{La comunicación popular y su importancia para el trabajo social comunitario}

El trabajo comunitario se ha caracterizado por ser unos de los principales componentes del quehacer profesional del trabajo social, pues además de que la comunidad aparece como un escenario complejo, contradictorio, histórico y en donde las manifestaciones de la "cuestión social” se expresan de manera mucho más marcada, se identifica por ser el lugar propicio para avanzar en la configuración, fortalecimiento y direccionamiento de los procesos organizativos. De igual manera, es menester señalar que la comunidad se encuentra directamente relacionada con el territorio, es decir, la configuran unas relaciones, vínculos, particularidades, costumbres, intereses comunes, entre otros, que llevan a entenderla como algo que se encuentra en constante movimiento, que está viva y tiene su propia historia hecha por hombres a partir de la cultura, se construye desde intereses, necesidades, capacidades y potencialidades colectivas, materializándose por medio del poblamiento, la cultura, la economía, el lenguaje, el trabajo, la política, entre otros aspectos. Por esto, cabe señalar que la comunidad es la base fundamental para la realización de los proyectos de vida mancomunados, es un espacio construido a partir de unas relaciones culturales, sociales, políticas y económicas, es el escenario donde se construye la vida, la familia, se crea sociedad y visiones de mundo compartidas.

En aras de fortalecer el trabajo comunitario, de reconocer, comprender y entrever las particularidades que caracterizan a las comunidades, aparece la comunicación popular como estrategia para encarar los procesos de cambio, de transformación social que allí se presentan, se constituye en oportunidad real para hacer visibles los procesos organizativos, pero también para visibilizar las experiencias que se adelantan por parte de los profesionales en y con las comunidades, posibilitando a la vez la formación, politización, organización y movilización social; se constituye en opción para fomentar la identidad y la diversidad cultural, generando espacios de diálogo y de acción entre los sujetos para avanzar en la construcción de propuestas colectivas, siendo así mismo estrategia de resistencia u de oposición al poder hegemónico. 
La comunicación popular como estrategia comunicacional, permite reflejar la realidad de las comunidades, el pensamiento no de personas sino de todo un colectivo, por lo tanto, es esencial que sea la comunidad la que se apropie de la misma con el acompañamiento del profesional social y, en esa medida, es importante que desde el trabajo social se comience a integrar a la formación y a la praxis profesional ${ }^{5}$, pues se deben vislumbrar estrategias innovadoras para la acción de los individuos, enmarcadas en la proposición de alternativas creadoras, reflexivas, críticas e inventivas, siendo el resultado del trabajo colectivo que se gesta a partir de la propia dinámica de la vida social. En ese sentido:

\begin{abstract}
Las alternativas no salen mágicamente de la galera del Asistente Social; las posibilidades están dadas en la realidad, pero no son automáticamente transformadas en alternativas profesionales. Cabe a los profesionales aprovecharse de esas posibilidades y, como sujetos, desarrollarlas, transformándolas en proyectos y frentes de trabajo. (Iamamoto, 2003, p. 34)
\end{abstract}

Se concibe como estrategia para expresar ideas, propuestas, reclamos, inconformidades, visibilizar las manifestaciones de la "cuestión social”, adicionalmente, para participar activamente de debates o diálogos en el espacio público; de modo que como lo expresa la Facultad de Ciencias Sociales de la Universidad de Buenos Aires, a través de su curso anual de comunicación popular "la comunicación comunitaria, popular y educativa es producto de una praxis, de un largo proceso de síntesis cultural, social y político comunicacional, que involucra participación, interacción y encuentro con la comunidad" (Facultad de Ciencias Sociales de la Universidad de Buenos Aires, 2014, p. 9), facilitando de esa manera, la construcción de vínculos desde la práctica educativa, aquella que implica reflexión sobre las mismas prácticas.

Ahora bien, el integrar a la formación curricular nuevas estrategias teórico-metodológicas profesionales que permitan comprender y aportar al trabajo comunitario, no solo aparece como desafío sino que es una necesidad que impone actualmente la contemporaneidad a las escuelas de trabajo social y a las mismas ciencias sociales, en ello, la comunicación popular se convierte en una de las tantas respuestas a tal requerimiento; si se observa la malla curricular de la Escuela de Trabajo Social de la Universidad Nacional de Colombia ${ }^{6}$, se comprende el avance significativo que se ha venido teniendo en dicho claustro académico en términos formativos con respecto a la comunicación y educación popular, pues se han integrado los

\footnotetext{
${ }^{5}$ Desde Adolfo Sánchez Vásquez la praxis se entiende como aquella crítica de la realidad concreta, pero también la autocrítica. Concibiéndose como una actividad práctica que se hace y rehace cosas, siendo a la vez algo más que práctica o su unidad con la teoría, pues es una práctica que aspira radicalmente a mejorar una sociedad, es la articulación consciente entre el pensamiento y la acción. Praxis es trabajo y el trabajo es la unión entre la idea y el acto concreto (Sánchez, 2011).

${ }^{6}$ Para mayor claridad, revisar malla curricular de Trabajo Social, Universidad Nacional de Colombia en http://www.humanas. unal.edu.co/2017/unidades-academicas/departamentos/trabajo-social/application/files/7515/2573/0893/plan-deestudios.pdf
} 
La comunicación popular como escenario de praxis para el trabajo social comunitario

principios teórico-metodológicos de éstas en una materia disciplinar correspondiente a la línea de "Teorías y Metodologías de Trabajo Social”, que debe ser vista por estudiantes de sexto semestre cuatro horas semanales, lo que otorga a la vez tres créditos educativos.

Este tipo de iniciativas curriculares deben servir de referente para otras escuelas de trabajo social, sobre todo para el área sociohistórica del trabajo comunitario, estructuradas a partir de líneas temáticas que integran conocimientos y habilidades necesarios para la formación profesional con el fin de avanzar en el proceso de descifrar la vida en sociedad. Se requiere desarrollar prácticas comunitarias creativas que además de articular pensamiento y acción, sean del interés de las comunidades, que reflejen lo que estas son en su cotidianidad, pues ellas producen significados, símbolos, mensajes, son cultura, resistencia, trabajo colectivo, lucha y han configurado diversas formas de organización popular, las cuales deben fortalecerse, pero así mismo, hacerlas visibles, pues se constituyen en expresiones colectivas, formas diversas de relación y articulación que se han construido con otros en escenarios de diálogo y participación.

\section{El quehacer del Trabajo Social en las luchas sociales desde el escenario de la comunicación popular}

Desde nuestro quehacer profesional como trabajadores sociales, y de acuerdo con autores como Marilda Iamamoto y José Paulo Netto, es necesario que se asuma una posición política para así avanzar en la consolidación de un proyecto organizativo que se desarrolle en el seno de las comunidades y se encuentre enmarcado desde una posición ético-política, en la que el trabajador social se inserte de manera clara con un objetivo aunado al proyecto de los sectores urbano populares, por ello, se debe partir por analizar el campo de contradicciones que caracterizan al capitalismo en su fase actual y a la profesión, signadas de prácticas en el que la maniobra del capital ha sido causante de sus mismos errores y de la construcción de alternativas que articulan educación, política y cultura desde el reconocimiento de la subjetividad e intersubjetividad, para visibilizar la identidad histórica como sujetos sociales que se unen por procesos comunicativos, a la par del lenguaje, jerga y prácticas creadoras de una identidad genérica y de carácter popular.

Por lo tanto, el trabajador social se incorpora en esta esfera para la gestación de una comunicación distinta a la promovida desde las clases dominantes, nuevas propuestas de contenidos que se ponen de manifiesto desde la vivencia y la exploración de una sociedad diferente a la imperante; este estadio es el intento de desnudar la realidad, aprehenderla y construirla desde la base, desde el diálogo, el debate, desde la vida cotidiana de la comunidad, desde la exigencia lingüística por develar y reconstruir una dialéctica que trace una reflexión crítica de cara a una condición humana que experimente otras dimensiones desde la conciencia social. 
Una dialéctica que politice los sectores populares para seguir labrando una cultura política destinada a confrontar la ideología neoliberal y capitalista cuyos nexos son intransigentes para la sociedad en general, que paulatinamente se organiza y se forma desde la aproximación conceptual para constituir las "armas de lucha", lo que sintetiza que "las [clases dominantes] no solo han forjado las armas que le darán muerte; también engendraron a los hombres que manejaron esas armas: [La sociedad moderna]" (Marx, 1983, p. 47), reflejado en el poder comunal de los pueblos indígenas, organizaciones sociales y populares, feministas, campesinas, productores, trabajadores, estudiantes, de la misma comunidad, que son los protagonistas para llevar a cabo esta propuesta de comunicación popular a la cuadra, a la vereda, al barrio, a la comuna, desde el periódico, la radio, grafiti, la televisión comunitaria, el teatro, el cine, la narrativa oral, para que ellos las apropien como expresiones inagotables y productoras de un escenario vasto para leer e interpretar la realidad concreta y así comenzar a transformar las relaciones sociales imperantes. Ahí aparece para la profesión el papel que debemos desempeñar como educadores políticos y defensores de los intereses de las comunidades con las que adelantamos nuestro quehacer profesional.

Las luchas sociales por la defensa del territorio, la vida digna, el derecho a organizarse, por la presencia real del Estado colombiano en los territorios, entre otras, se convierten en escenarios en los cuales los profesionales debemos estar inmersos materializando proyectos de comunicación popular, de la mano de organizaciones sociales, barriales y, por ende, desde las mismas comunidades, haciéndole contraofensiva a la guerra cultural llevada a cabo por las clases dominantes a través de los medios masivos de comunicación, porque así como lo manifiesta Aharonian (2007): "No hay que olvidar que una de las tácticas del poder mediático es deslegitimar ideológica y políticamente a las organizaciones sociales, para dividirlas, aislarlas y restarles apoyo social" (p. 64).

La praxis comunicacional no puede dejar de ser una tarea pendiente para las comunidades, organizaciones sociales, y por ende, para los trabajadores sociales, estamos llamados a integrarla como estrategia para la educación, organización y movilización popular, ya que la mundialización de las luchas sociales implica la mundialización de las luchas de ideas y, en particular, de la disputa por lograr el acceso a amplios públicos, la batalla por comunicar.

En el campo de este tipo de comunicación, los profesionales pueden y deben aportar desde lo teórico, pero también desde lo metodológico y lo organizativo a desarrollar una nueva cultura, una participación activa de los sectores populares, un sentido crítico de las prácticas comunicativas y, de esa manera, se puedan construir unas nuevas, en mediación con una pedagogía de comunicación tomada desde la educación popular, la investigación y la acción participativa que condense la historia, la actualidad, la utopía como escenarios para potenciar la creatividad y la identidad desde el reconocimiento de necesidades y posibilidades de las comunidades, de modo que la comunicación popular se convierta en escenario de praxis 
trasformadora para el trabajo social en la búsqueda de la justicia social, de la emancipación política y, ¿por qué no?, de la emancipación humana.

\section{Conclusión}

En este momento en que cobra fuerza el debate de la formación profesional, producto de la actualización de los planes curriculares que se viene planteando en varias escuelas nacionales de trabajo social, es importante examinar las exigencias que le hacen a la profesión las contradicciones presentes en el mundo del trabajo, avanzándose en la construcción de una propuesta de formación profesional que obedezca a las dinámicas de los nuevos tiempos, coherente con el discurso que promulgamos y comprometida con la construcción de una sociedad realmente digna y justa. Se debe pensar la formación y el quehacer profesional en el presente, es decir, partiendo del reconocimiento de las nuevas demandas que se le presentan al trabajo social, para así formular propuestas teórico-metodológicas que respondan a aquellas demandas de las poblaciones.

En el ámbito comunitario, el desafío es definir prácticas profesionales que vislumbren alternativas creativas y novedosas que además de visibilizar las problemáticas condiciones de vida, resalten las capacidades de las comunidades y le apuesten a las luchas sociales y a la organización, comprometidas con la implementación de propuestas de acción devenidas desde los mismos individuos. Es en este sentido, que la comunicación popular aparece como estrategia, como táctica para combatir la simulación creada por los medios de comunicación masiva, contribuyendo a la producción de un nuevo tipo de signos, símbolos, lenguajes (no parcializados), para lograr recuperar la esperanza y la utopía que han sido expulsados de la sociedad, para atacar la distorsión y manipulación de lo real.

Aparece para contribuir a que los sujetos puedan describir su identidad y el dominio simbólico, alcanzar la expansión de sus libertades reales (libertades políticas, económicas, sociales y culturales) pero, básicamente, para surgir desde la misma comunidad organizada, sea desde los procesos barriales o rurales; le entrega un rol protagónico a las comunidades, puesto que además de informar y denunciar lo que acontece en su mundo comunitario, se convierte en un medio que contribuye a la educación, a la formación política y a la organización de los sectores populares, a la reivindicación de derechos y la conquista de otros, contribuyendo de ese modo a la construcción de una sociedad distinta. Es el momento que desde la profesión se integre al pensamiento, pero también a la acción de forma articulada en el marco del trabajo comunitario la comunicación popular. 


\section{Referencias}

Abad, F. (2006).Filosofía de la Comunicación. Recuperado de www.mci.gob.ve;publicaciones@ mci.gov.ve.

Aharonian, A. (2007). Vernos con nuestros propios ojos: apuntes sobre comunicación y democracia. Caracas, Venezuela: Fundación Editorial el Perro y la Rana.

Antunes, R. (2001). ¿Adiós al trabajo? Ensayo sobre la metamorfosis y la centralidad del mundo del trabajo. Sao Paulo, Brasil: Cortez Editora.

Barbero, J. (1983). Comunicación popular y los modelos trasnacionales. Quito, Ecuador: Chasqui $N^{\circ} 8$, CIESPAL.

Facultad de Ciencias Sociales de la Universidad de Buenos Aires. (2014). Comunicación popular, educativa y comunitaria. Buenos Aires. Recuperado de http://www.sociales.uba.ar/wpcontent/blogs.dir/219/files/2015/07/6-Comunicacion-B.pdf.

Iamamoto, M. (2003). El servicio social en la contemporaneidad: trabajo y formación profesional. São Paulo, Brasil: Cortez Editora.

Infranca, A. (2006). Trabajo, individuo, historia: El concepto de trabajo en Lukács. Caracas, Venezuela: Monte Ávila Editores.

Jaramillo, J. (2012). El campo Urbano-Popular: nuevos paradigmas de análisis. Revista Ciudad Paz-ando, 5, 7-30.

Marx, C. y Engels, F. (1976). La Ideología Alemana, en obras escogidas en tres tomos, Tomo I. Moscú, Rusia: Editorial Progreso.

Marx, C. (1983). Manifiesto del partido comunista. Madrid, España: Altamira S.A.

Netto, J.P. (2003). Cinco notas a propósito de la cuestión social. En E. Borgianni., Y. Guerra. y C. Montaño. (Eds.), Servicio Social Crítico (pp. 55-69). Sao Paulo, Brasil: Editora Cortez.

Sánchez, A. (2011). Filosofía de la praxis. México, D.F., México: Siglo XXI Editores. 